\title{
BERICHTIGUNGEN UND ERGÄNZUNGEN.
}

S. 36 Zeile 19 von oben lies Landgrafen statt Langrafen.

" 136 Anm. 1 ist hinter Ende 1535 einzuschalten : und April 1536.

" 138 Zeile 5 von oben lies wan es ouch, als statt wan es ouch als.

- 190 am Rande lies p. 198 A. 2 statt p. 189 A. 2.

- 190 Anm. 2. Die Conjectur Nassach u. Musberg für Nassen u. Musselberg ist kaum aufrecht zu erhalten. Wie auf Seite $409 \mathrm{Anm}$. 1 ausgeführt ist, haben wir unter Musselberg wahrscheinlich Pont à Mousson zu verstehen. Für Nassen ist dann kaum eine andere Erklärung möglich, als dass damit Nancy (Nanzig) gemeint, u. dass der Name durch Gedankenlosigkeit des Schreibers verunstaltet ist.

*208 Anm. 2 lies Claudius von Guise, Bruder des Herzogs Anton statt Cardinal Karl von Guise, Bruder des Herzogs Franz.

- 316 Zeile 19 von oben lies von kaiserlicher mat. zu begeren. so wer etc. statt von kaiser licher mat. zu begeren so wer etc.

^320 Leider zu spät sehe ich, dass der Wiener Vertrag schon von Waltz im 13. Bande der «Forschungen» abgedruckt ist. In seinen daran geknüpften Erörterungen gelangt Waltz dazu, Rankes Auffassung bestätigt zu finden und Sleidan der Unzuverlässigkeit zu zeihen. Die Verkehrtheit diescr Folgerungen werde ich demnächst an andrer Stelle ausführlicher darthun.

" 379 Der Brief nr. 390 ist in der lateinischen Fassung gedruckt in Calvini opera X 57 .

^394 Der Brief nr. 414 findet sich nach dem Original vollständig abgedruckt in Calvini opera X 68 .

\406 Anm. 1 lies Claudius von Guise statt der Cardinal Karl von Guise.

- 414 Nr. 439. Aus der Relation Pfarrers über den Schmalkaldischen Tag giebt Kolde Analecta Lutherana p. 296 einen Auszug. Bezüglich des letzteren ist zu bemerken, dass der Herausgeber auf Seite 297 Zeile 14 von unten eine Zeile des Originals aus Versehen übersprungen hat, ebenso auf Seite 298 Zeile 3 des Textes von unten einige Worte, welche man nach unserm Abdruck ergänzen mag.

D462 Anm. Zeile 10 von oben lies Felix Icher statt Felix Scher.

»462 Anm. Zeile 16 von oben lies Band I p. 249 anstatt Band I p. 269. 
